\title{
Generation, annotation, analysis and database integration of 16,500 white spruce EST clusters
}

Nathalie Pavy*1, Charles Paule2, Lee Parsons², John A Crow², MarieJosee Morency ${ }^{3}$, Janice Cooke ${ }^{1,5}$, James E Johnson ${ }^{2}$, Etienne Noumen ${ }^{1}$, Carine Guillet-Claude ${ }^{1}$, Yaron Butterfield ${ }^{4}$, Sarah Barber ${ }^{4}$, George Yang ${ }^{4}$, Jerry Liu ${ }^{4}$, Jeff Stott ${ }^{4}$, Robert Kirkpatrick ${ }^{4}$, Asim Siddiqui ${ }^{4}$, Robert Holt ${ }^{4}$, Marco Marra ${ }^{4}$, Armand Seguin ${ }^{3}$, Ernest Retzel ${ }^{2}$, Jean Bousquet ${ }^{1}$ and John MacKay ${ }^{1}$

Address: ${ }^{1}$ ARBOREA and Canada Research Chair in Forest Genomics, Pavillon Charles-Eugène-Marchand, Université Laval, Ste.Foy, Québec G1K 7P4, Canada, ${ }^{2}$ Center for Computational Genomics and Bioinformatics, University of Minnesota, 420 Delaware St. S.E., MMC 43, Minneapolis, MN 55455, USA, ${ }^{3}$ Laurentian Forestry Center (Canadian Forestry Service), Natural Resources Canada, 1055 rue du PEPS, Québec, Québec, G1V 4C7, Canada, ${ }^{4}$ Genome Sciences Center, BC Cancer Agency, 675 West 10 th Avenue, Vancouver, BC, V5Z 1L3, Canada and ${ }^{5}$ Department of Biological Sciences, University of Alberta, Edmonton, Alberta, T6G 2E9, Canada

Email: Nathalie Pavy* - nathalie.pavy@rsvs.ulaval.ca; Charles Paule - cpaule@mail.ahc.umn.edu; Lee Parsons - lparsons@mail.ahc.umn.edu; John A Crow - crow@mail.ahc.umn.edu; Marie-Josee Morency - mjmorency@exchange.cfl.forestry.ca; Janice Cooke - janice.cooke@ualberta.ca; James E Johnson - jj@ccgb.umn.edu; Etienne Noumen - enoumen@rsvs.ulaval.ca; Carine Guillet-Claude - cguillet@rsvs.ulaval.ca; Yaron Butterfield - ybutterfield@bcgsc.ca; Sarah Barber - sbarber@bcgsc.ca; George Yang - gyang@bcgsc.ca; Jerry Liu - jliu@bcgsc.ca; Jeff Stott - jstott@bcgsc.ca; Robert Kirkpatrick - rkirkpatrick@bcgsc.ca; Asim Siddiqui - asiddiqui@bcgsc.ca; Robert Holt - rholt@bcgsc.ca; Marco Marra - mmarra@bcgsc.ca; Armand Seguin - ASeguin@exchange.cfl.forestry.ca; Ernest Retzel - ernest@mail.ahc.umn.edu; Jean Bousquet - bousquet@rsvs.ulaval.ca; John MacKay - jmackay@rsvs.ulaval.ca

* Corresponding author

Published: 19 October 2005

BMC Genomics 2005, 6:144 doi:10.1/86//47|-2164-6-144
Received: 17 August 2005

Accepted: 19 October 2005

This article is available from: http://www.biomedcentral.com/I47I-2/64/6/I44

(c) 2005 Pavy et al; licensee BioMed Central Ltd.

This is an Open Access article distributed under the terms of the Creative Commons Attribution License (http://creativecommons.org/licenses/by/2.0), which permits unrestricted use, distribution, and reproduction in any medium, provided the original work is properly cited.

\begin{abstract}
Background: The sequencing and analysis of ESTs is for now the only practical approach for largescale gene discovery and annotation in conifers because their very large genomes are unlikely to be sequenced in the near future. Our objective was to produce extensive collections of ESTs and cDNA clones to support manufacture of cDNA microarrays and gene discovery in white spruce (Picea glauca [Moench] Voss).

Results: We produced 16 cDNA libraries from different tissues and a variety of treatments, and partially sequenced 50,000 cDNA clones. High quality $3^{\prime}$ and $5^{\prime}$ reads were assembled into 16,578 consensus sequences, $45 \%$ of which represented full length inserts. Consensus sequences derived from 5 ' and $3^{\prime}$ reads of the same cDNA clone were linked to define $14,47 \mid$ transcripts. A large proportion (84\%) of the spruce sequences matched a pine sequence, but only $68 \%$ of the spruce transcripts had homologs in Arabidopsis or rice. Nearly all the sequences that matched the Populus trichocarpa genome (the only sequenced tree genome) also matched rice or Arabidopsis genomes. We used several sequence similarity search approaches for assignment of putative functions, including blast searches against general and specialized databases (transcription factors, cell wall related proteins), Gene Ontology term assignation and Hidden Markov Model searches against
\end{abstract}


PFAM protein families and domains. In total, $70 \%$ of the spruce transcripts displayed matches to proteins of known or unknown function in the Unirefl 00 database (blastx e-value < Ie-10). We identified multigenic families that appeared larger in spruce than in the Arabidopsis or rice genomes. Detailed analysis of translationally controlled tumour proteins and S-adenosylmethionine synthetase families confirmed a twofold size difference. Sequences and annotations were organized in a dedicated database, SpruceDB. Several search tools were developed to mine the data either based on their occurrence in the cDNA libraries or on functional annotations.

Conclusion: This report illustrates specific approaches for large-scale gene discovery and annotation in an organism that is very distantly related to any of the fully sequenced genomes. The ArboreaSet sequences and cDNA clones represent a valuable resource for investigations ranging from plant comparative genomics to applied conifer genetics.

\section{Background}

Genomics projects have been initiated in several pine and spruce species to identify genes involved in traits of economic interest and of ecological significance in conifers. It is unlikely, however, that conifer genomes will be completely sequenced in the near future because of their shear size [1]. For example, estimates of the haploid DNA content of Pinus taeda ranged from $11 \mathrm{pg}$ [2] to $23.2 \mathrm{pg}$ [3] and that of Picea glauca ranged between $4.5 \mathrm{pg}$ [4] to 20.2 pg [PGI5.0; [5]]. With around 10-20,000 Mb [6], conifer genomes are more than 100 times larger than that of Arabidopsis and three times larger than the human genome. Such a large genome suggests that strategies that aim at characterizing the coding component of the genome will be more cost efficient for the recovery of information, in the short term.

The large-scale sequencing and analysis of ESTs remain a fundamental part of genomics research to enable gene discovery and annotation in most forest tree species, but especially in conifers. Several EST sequencing projects have been initiated in pines; 191,229 ESTs from several species were assembled to produce 35,053 consensus sequences in the Pinus Gene Index [7]. A large majority of conifer sequences were shown to have sequence similarity to Angiosperm genes or genome sequences like Arabidopsis, however the identification of homologous sequences depends largely on the length of sequences available to conduct similarity searches [8,9]. In loblolly pine, for example, the majority of contigged sequences which had no sequence similarity to other genomes were very short and more than $90 \%$ of sequences above $1 \mathrm{~kb}$ in length gave strong matches to Arabidopsis [8]. Therefore, effective annotation of conifer coding sequences through comparative approaches is best achieved with complete information, which may be obtained by combining $3^{\prime}$ and $5^{\prime}$ sequences or by full length sequencing strategies. A recent investigation of the knox gene family in conifers showed that gene evolution and conifer protein family structure may diverge quite significantly from those of Angiosperm genomes [10]. It is unknown how widespread this phe- nomenon may be; however, the finding suggests that although conserved protein motifs may be unambiguously identified, the biological role of genes belonging to conifer protein families may not be readily inferred from their Angiosperm homologs. These data would support the argument in favour of thorough cDNA sequencing projects in conifers because they are distantly related to model Angiosperms like Arabidopsis, in order to fully characterize protein families.

Many conifer EST sequencing projects have focused on wood formation and secondary xylem in pines (e.g. due to the ecological significance of the genus and the economic importance of wood $[8,11])$. More recently, programs have emerged that involve other species including Douglas-fir [12] and spruce [13], and address other important aspects of tree physiology like the response to abiotic stresses or biotic stresses $[12,14]$. Macroarrays and microarrays ranging in scope from a few hundred to a few thousand genes have been developed to help identify genes involved in wood formation and to characterize their putative roles in determining wood quality (e.g. in maritime pine [15], and in loblolly pine [16]). The relatively high level of sequence similarity between genera within the Pinaceae family has lead to the use of loblolly pine arrays for expression profiling experiments in scots pine, norway spruce [17] and white spruce [18]. Transcript profiling has also been integrated into investigations of xylem differentiation in poplar [19], different questions related to wood formation have also been investigated by transcript profiling in Angiosperm trees, including heartwood of black locust trees [20], tissue differentiation in poplar [19] and tension wood formation in Eucalyptus [21].

Spruce is the most widely used genus for forest tree plantations in Canada, with hundreds of million seedlings planted each year [22]. It is also widely divergent from pine $[23,24]$. Genetic improvement of spruce species, mainly white and black spruces, has been ongoing in Canada since the 1950s and extensive information has been accumulated on the genetic control of commercially 
Table I: Sequencing and quality parameters of white spruce cDNA libraries. Quality reads had a Phred score above 20 over at least 100 bp after vector trimming.

\begin{tabular}{|c|c|c|c|c|c|c|c|}
\hline \multirow[t]{2}{*}{ Libraries, treatments and tissues } & \multicolumn{2}{|c|}{ Number of reads } & \multicolumn{2}{|c|}{ Library quality } & \multicolumn{3}{|c|}{ Sequence quality } \\
\hline & $3^{\prime}$ & $5^{\prime}$ & \% Empty & $\%>1.6 \mathrm{~Kb}$ & $\begin{array}{l}\mathrm{Nb} \text { of quality } \\
\text { reads }\end{array}$ & \% Quality reads & $\begin{array}{c}\text { Average length } \\
\text { of quality reads } \\
\text { (nt) }\end{array}$ \\
\hline Male strobili development sequence & I,536 & I,536 & 4 & 19 & 2,589 & 84 & 527 \\
\hline Female cones development sequence & 1,536 & 1,536 & 15 & 9 & 2,324 & 76 & 500 \\
\hline Vegetative buds development sequence & 1,536 & 0 & 5 & 15 & 1,062 & 69 & 560 \\
\hline Secondary xylem - mature trees & 4,608 & 4,608 & 10 & 27 & 7,735 & 84 & 600 \\
\hline Cambium, phloem - mature trees & 4,608 & 3,072 & 2 & 8 & 6,705 & 87 & 635 \\
\hline Secondary xylem - girdled seedlings & 3,072 & 0 & 9 & 24 & $\mathrm{I}, 053$ & 69 & 556 \\
\hline Cambium to bark - girdled seedlings & 1,536 & 1,536 & NA & NA & 937 & 31 & 577 \\
\hline Elongating root tips - saplings & 1,536 & 1,536 & 6 & 19 & 1,053 & 69 & 395 \\
\hline Primary, secondary shoots- $\mathrm{N}$ treatments & 3,072 & 1,536 & 16 & 50 & 3,031 & 66 & 736 \\
\hline Immature somatic embryos & 3,072 & 0 & 4 & 44 & 2,220 & 72 & 692 \\
\hline Clean roots systems $-\mathrm{N}$ treatments & $\mathrm{I}, 536$ & 0 & 7 & 37 & 858 & 56 & 659 \\
\hline Clean roots systems $-\mathrm{P}$ treatments & 3,072 & 1,536 & 15 & 19 & 3,776 & 82 & 705 \\
\hline Clean roots systems - Diurnal cycle & 6,144 & 4,608 & 16 & 33 & 8,601 & 80 & 757 \\
\hline Root secondary xylem - mature trees & 3,072 & 0 & 7 & 8 & 1,532 & 50 & 598 \\
\hline Annual flush shoots diurnal cycle - trees & 4,608 & 3,072 & 11 & 10 & 5,164 & 67 & 658 \\
\hline Needles - $\mathrm{N}$ fertilization treatments & $\mathrm{I}, 536$ & 0 & 15 & 20 & 461 & 30 & 686 \\
\hline Total & 46,848 & 24,576 & & & 49,101 & & \\
\hline
\end{tabular}

important traits. Genome mapping of spruces is underway to enable molecular breeding applications (e.g. [25]). Association mapping approaches have been proposed as most promising to identify genes underlying phenotypic variation in quantitative traits, and thus, to support the development of molecular breeding strategies in conifers [26]. Large-scale EST sequencing and analysis are expected to enable association studies and gene mapping research as they are prerequisite steps to identifying SNPs to use in high throughput genotyping assays.

The objective of this study was to produce extensive collections of EST sequences and CDNA clones to support manufacture of cDNA microarrays and gene discovery efforts in white spruce (Picea glauca [Moench] Voss). This collection of ESTs constitutes an important new resource for the genomics of white spruce and related species. In this paper, we report the sequence analysis of around 71,000 sequence reads obtained through $3^{\prime}$ and $5^{\prime}$ sequencing of cDNAs. Comparative analyses were conducted to assign a functional annotation based upon similarities. Spruce contigs were also correlated with terms derived from the Gene Ontology [27], and similarity searches were conducted against specialized databases to identify putative transcription factors, cell wall related proteins and protein domains available in PFAM. To mine this new sequence resource, a database called SpruceDB

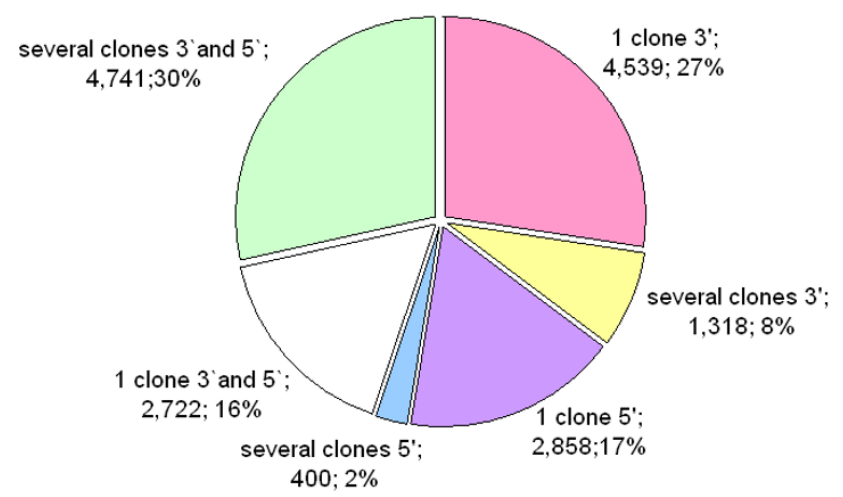

Figure I

Composition of white spruce consensus sequences (contigs and singletons) according to orientation of direction of the reads $\left(3^{\prime}\right.$ or $\left.5^{\prime}\right)$ and according to their redundancy in the database (number of clones).

has been developed at the Center of Computational Genomics and Bioinformatics (CCGB, University of Minnesota) [28], which supports multiple queries on the occurrence of the ESTs in the libraries and on the functional annotations. 


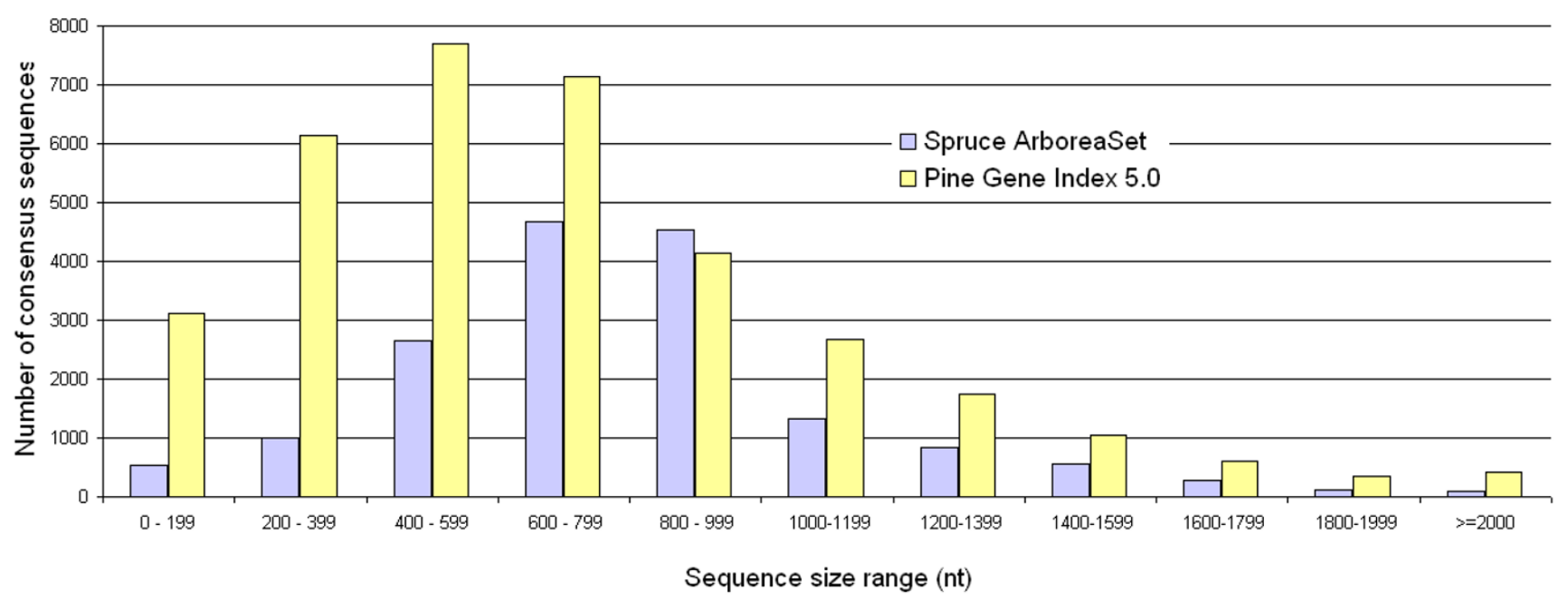

Figure 2

Sequence sizes. Size distribution of the consensus sequences derived from the pine (PGI5.0) and white spruce (ArboreaSet) assemblies.

\section{Results and discusion}

Library development and resulting sequences

Tissue sampling and EST sequencing strategies

The cDNA libraries were developed with the goal of augmenting the representation of conifer transcripts available in public databases, and to support experimental goals related to vascular development. We sequenced ESTs from 16 non-normalized cDNA libraries, synthesized from diverse spruce organs and tissues, and representing various stages of development from immature embryos to 30 year-old trees in diverse growth conditions (Table 1) [see also Additional file 1].

We sequenced close to 50,000 cDNA clones, sampling between 1,536 and 6,144 clones from each cDNA library. The library quality assessment data, the number of sequencing reactions, and the number of high quality reads for each library are presented in Table 1 . All clones were sequenced from the 3 ' end ; in addition, 5' sequencing was carried on many clones from the libraries of highest quality or most relevant to our research goals. In total, 71,424 reads were obtained and processed to remove vector and sequences of low quality (Phred score below 20). We thus retained 49,101 quality reads (QR) comprised of at least 100 contiguous nucleotides with a Phred score above 20 (Table 1). Among the quality reads 33.5\% were from secondary vascular tissues, $32.2 \%$ were from roots, $16.7 \%$ from young shoots (all tissues), and the remaining $17.6 \%$ were from various organs including male strobili, female cones, buds, somatic embryos, and needles (Table 1).
EST assembly into contigs

The assembly of the 49,101 quality reads resulted in 9,354 contigs and 7,224 singletons, representing a total of 16,578 consensus sequences named ArboreaSet in the following. As a result of our sequencing strategy, 46\% of the consensus sequences were derived from overlapping 3' and 5 ' reads of one or more cDNA clones (Figure 1 ). We considered that non-overlapping 3'and 5' reads derived from the same cDNA clone (i.e. a spanning clone) belonged to the same transcript. We thus used spanning clones to link several consensus sequences and obtained a reduced set of 14,471 sequences that we defined as "transcripts".

The proportion of consensus sequences represented by more than one cDNA clone was only 39\%, which provides an estimate of the sequencing redundancy. The bidirectional sequencing strategy and the average length of quality reads (Table 1) also impacted upon the length distribution of consensus sequences. The most striking feature of the set of spruce consensus sequences is the small proportion of sequences under 600 nucleotides compared to the PGI5.0 pine sequence assembly (mainly derived from 5' reads) despite its much larger number of sequences (Figure 2). The average consensus lengths were 797 and 690 nucleotides, for the Arborea and PGI5.0 sets, respectively; the median lengths were 784 and 612 nucleotides for these same datasets. The deepest contigs in the ArboreaSet included sequences homologous to genes coding for a DNA methylase (202 clones), the translation elongation factor-1 alpha (111 clones), a polyubiquitin 
Table 2: Contig groups according to several levels of sequence identity based on $100 \mathrm{nt}$ of overlap

\begin{tabular}{ccccc}
\hline $\begin{array}{c}\text { Number of contigs per } \\
\text { group }\end{array}$ & $90 \%$ & $96 \%$ & $98 \%$ & $99 \%$ \\
\hline 1 & 10,036 & 10,997 & 11,767 & 13,295 \\
2 & 1,576 & 1,422 & 1,377 & 3,083 \\
3 & 443 & 386 & 103 & 210 \\
4 & 175 & 153 & 48 & 22 \\
5 & 93 & 72 & 26 & 6 \\
6 & 52 & 40 & 10 & 2 \\
7 & 15 & 17 & 7 & 1 \\
8 & 13 & 1 & 3 & 1 \\
9 & 10 & 12 & 3 & 13 \\
\hline 10 & 21 & 13,109 & 13,686 & 14,685 \\
\hline
\end{tabular}

(68 clones), an homocysteine methyltransferase (68 clones), a S-adenosylmethionine synthetase (65 clones).

We also estimated the level of redundancy among the 16,578 consensus sequences by comparing the entire set of sequences to itself with the blastn program (Table 2). High scoring pairs revealing more than $98 \%$ of identity over more than 100 bp were used to define 13,686 contig groups, indicating a level of $21.1 \%$ of redundancy among the consensus sequences (Table 2). The very large majority of the 13,686 contig groups were comprised of one or two consensus sequences; however a few groups (3) were made up of more than ten distinct sequences. In a collection of 43,141 consensus sequences derived from 260,000 sugarcane ESTs, the redundancy was estimated at $22 \%$, based upon $98 \%$ over 100 bp [29]. In a Citrus EST sequence assembly, the level of redundancy was estimated at $25 \%$ [30]. Overall the redundancy is in the same range as observed in other projects conducted in mouse [31] or honey bee [32].

Spruce and pine EST datasets are populated with allelic variants for many loci because conifers are outbred and highly heterozygous. As a consequence, the number of genes sampled may be estimated more or less accurately from the number of contigs or contig groups, depending upon the parameters that are used for their assembly and clustering. To our knowledge, the impact of assembly parameters has not been directly assessed in conifers or other Gymnosperms. On the other hand, the average nucleotide diversity was reported to be low for conifers $[24,26]$; for example, sequence variation was estimated in pines with the average mutation population parameter $?=$ 0.00407 in Pinus taeda [33], $?=0.00241$ in $P$. pinaster, $?=$ 0.00186 in $P$. radiata [34] and $?=0.0013$ in $P$. sylvestris [35]. These data suggest that the use of stringent criteria were appropriate for the assembly (into contigs) of the spruce sequence dataset comprised in part of allelic sequences. We also defined contig groups with less stringent criteria aiming to evaluate sequence redundancy. We recognize, however, that some contigs may contain paralogs, especially for slow-evolving gene families as discussed in other reports on plant EST clustering [29,30]. For these reasons, the contig groups are thought to provide a conservative estimate of the number of genes, i.e. the minimum number of genes sequenced.

\section{Sequence comparisons with other species}

We performed sequence similarity searches using tblastx and blastx to compare the ArboreaSet to several sequence datasets from Angiosperms (Arabidopsis, rice, poplar) and Gymnosperms (Cycas and pine), and to the Uniref100 protein database for several e-value cutoffs (Figure 3). In the following sections, the data were obtained with an evalue cutoff of $1 \mathrm{e}-10$ unless specified otherwise.

\section{Sequence comparisons with the pine database and Angiosperm genomes}

We found that $84.4 \%$ the Arborea transcript set $(12,108$ transcripts) showed sequence similarity with a contig of the Pine Gene Index (PGI5.0) which contains the largest assembly of publicly available pine ESTs (Figure 3). All of the tblastx searches detected a greater number of matches with PGI5.0 than with the Uniref100 protein database, in which the PGI5.0 consensus sequences are not represented. We examined whether the lack of similarity of the remaining $15.6 \%$ spruce transcripts (with no counterpart in the pine database) could be attributed to the non overlap of pine and spruce contigs derived from $5^{\prime}$ and $3^{\prime}$ sequences, respectively. More than half of the non matching spruce transcripts ( $9.8 \%$ of the total transcripts) were indeed derived only from 3' reads. Therefore, the lack of similarity of many of the sequences is not sufficient to conclude whether a pine homolog is absent from the 


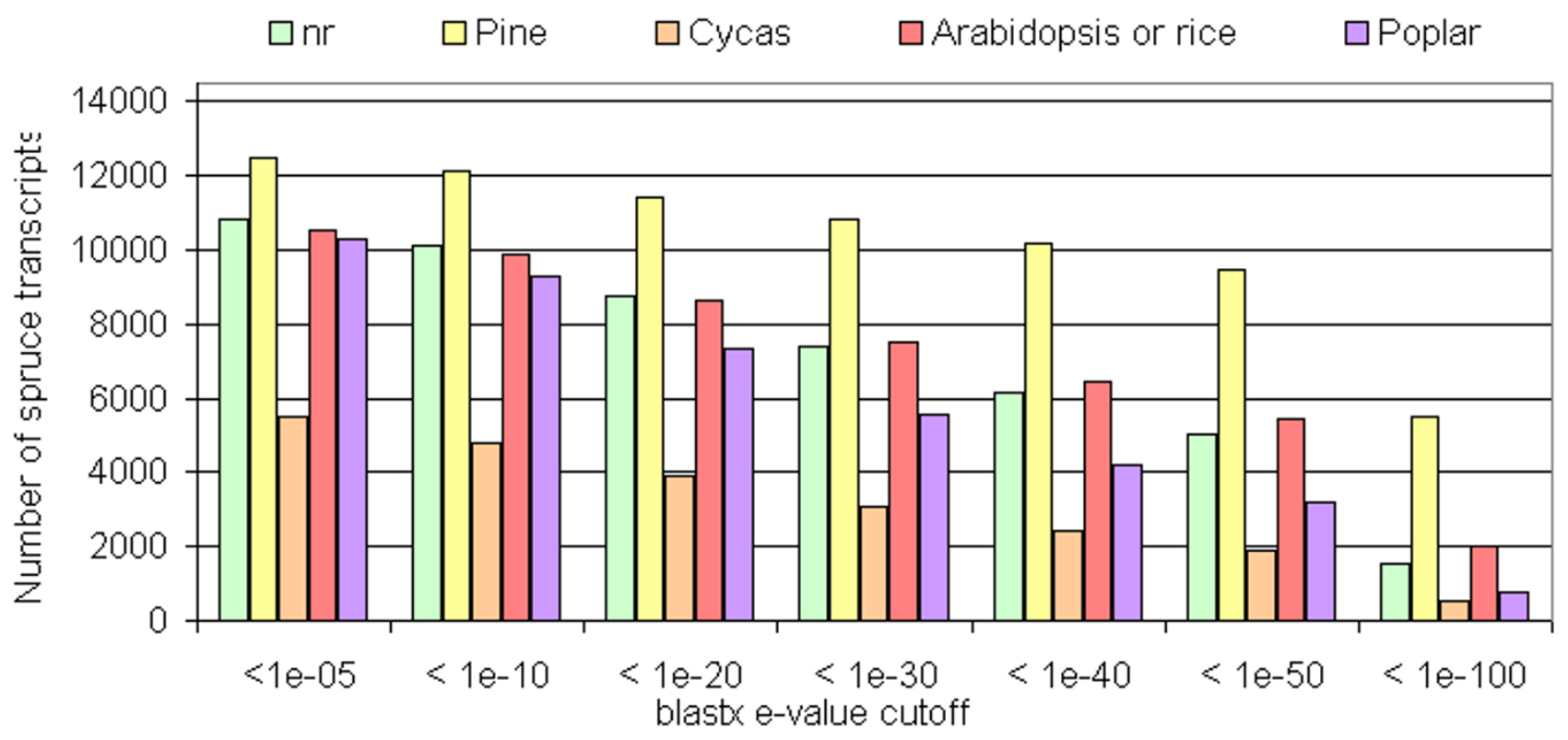

Figure 3

Sequence similarities. Number of white spruce transcript sequences similar to Unirefl 00 proteins, Arabidopsis, pine, Cycas according to the blast e-value cutoff.

database. Nonetheless, $6.6 \%$ of the spruce transcripts were derived from 5 ' reads alone (predominantly) or both ${ }^{\prime}$ ' and 3 ' reads and, did not match a pine contig. For these sequences, there is a high likelihood that a similar pine transcript has not been sequenced thus far.

As might be expected, the overall sequence similarity was lower with Angiosperms than pine sequences. There were fewer matches and the number of matches decayed more rapidly as we used more stringent e-value cutoffs with tblastx against Angiosperms sequences. At the protein level, $68.4 \%(9,898)$ of spruce transcripts matched a sequence from Arabidopsis or rice with a tblastx e-value < $1 \mathrm{e}-10$ and the proportion dropped to $37.6 \%$ for highly conserved sequences (e-value < 1e-50) compared to $65.3 \%$ with pine. A similar trend was observed with the poplar genome sequence which gave slightly lower similarities than Arabidopsis and rice sets, i.e. 64.3\% and 21.6\% matches with e-values below $1 \mathrm{e}-10$ and $1 \mathrm{e}-50$, respectively (Figure 3).

\section{Complementarity of the sequencing projects in several species}

We analyzed and compared the overlap of sequence datasets derived from spruce, pine, Arabidopsis, rice and poplar, to develop an overall understanding of the complementarity between the sequencing projects in these diverse species. The extent of the overlap based upon tblastx matches is shown in Figure 4. In total, $77.5 \%$ transcripts found both in pine and spruce databases $(9,384$ of 12,108) gave a match with Arabidopsis or rice. However, only $514(3.6 \%)$ spruce transcripts without any homolog in the pine database had a homolog in Arabidopsis or rice. In contrast, $41.7 \%$ out of the 26,616 consensus sequences from PGI5.0 that had no match in the ArboreaSet, gave a hit in Arabidopsis or rice. These sequence results appear consistent with the extent of divergence that might be expected between the genomes of Gymnosperms and Angiosperms. In a previous study, pine consensus sequences gave $61.5 \%, 59.4 \%$ and $55 \%$ matches against Arabidopsis, rice and poplar, respectively [9]. With the same similarity search parameters, the spruce transcripts which contains longer sequences on average - gave slightly more matches against Arabidopsis or rice (68.4\%), and as well as against poplar (64.3\%).

Comparisons to the poplar genome sequence gave fewer matches and only a small number of matches not identified with Arabidopsis or rice (Figure 4 ). Only $89.1 \%$ of the spruce transcripts $(8,823$ out of 9,898$)$ that matched an Arabidopsis or rice sequence also had a similarity to a sequence in the poplar genome. Furthermore, 3.5\% of the spruce transcripts which lacked similarity to Arabidopsis or rice gave a match against the poplar genome. In the end, sequence similarity searches against the poplar genome 


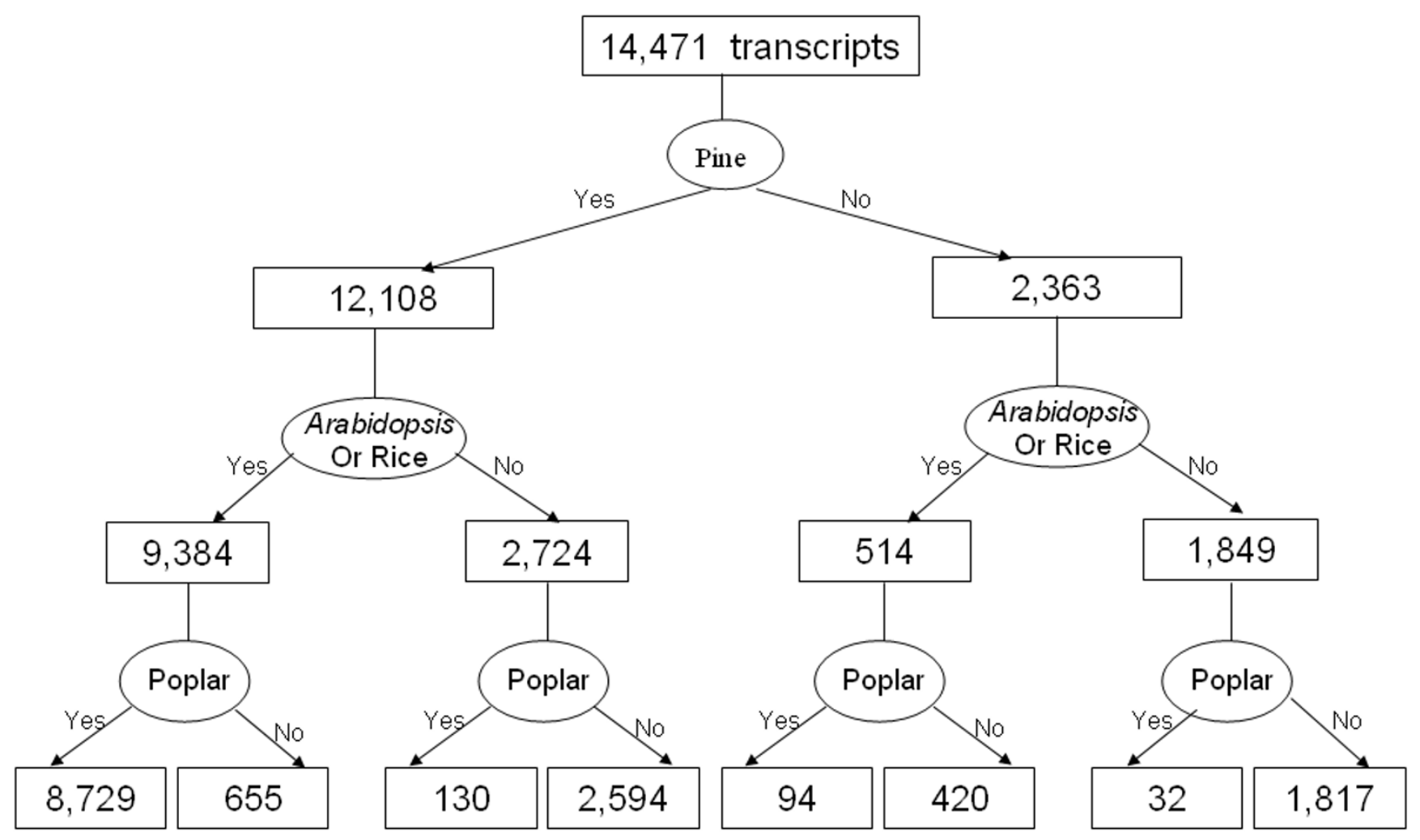

Figure 4

Hierarchical presentation of the number of spruce transcripts with or without similarities with pine, Arabidopsis, rice and poplar. The numbers were derived by the filtering of tblastx searches with an e-value $<1$ e- 10 .

only allowed us to annotate 162 additional sequences ( $0.7 \%$ of the spruce transcripts) compared to data derived from comparisons with Arabidopsis or rice. Such a trend is expected given the relatively close proximity between poplar (Salicaceae) and Arabidopsis (Brassicaceae).

The results indicate that data derived from Angiosperms species alone are insufficient for annotating sequences in conifers and that computational tools specifically developed for Gymnosperms are needed to help recognize functional regions in sequences like coding sequences or motifs in around 30\% of conifer sequences with no obvious counterpart in Angiosperms. For example, the software Diogenes for predicting open reading frames in sequences was trained based on Pinaceae derived sequences for this purpose [36].

\section{Functional annotation}

In total, $10,130(70 \%)$ of the spruce transcripts displayed matches to proteins of known or unknown function, based on the blastx analysis against the Uniref100 database. We conducted Hidden Markov Model (HMM) searches against the PFAM protein family database $[37,38]$ to evaluate the proportion of the spruce transcripts homologous to families with an assigned function. Overall, we found that $52 \%$ of the 14,471 spruce "transcripts" showed similarity with 1,655 PFAM protein families (p-score below 1e-10). There were 157 of these PFAM families annotated as "DUF, Domain of Unknown Function", which showed similarities with 488 transcripts, and 20 families annotated as "UPF, Uncharacterized Protein Family" showing similarities with 45 transcripts. In the end, a total $48 \%$ of the spruce transcripts were similar to 1,478 PFAM families when DUFs and UPFs were excluded.

A separate approach using the Gene Ontology scheme [27] categorized 39\% of the ArboreaSet contigs into 16 molecular functions based on similarity with functionally annotated genes in other organisms (Table 3). Functional categories were assigned by using the GO terms correlated to similar proteins from Uniref100 [39] or from the Arabidopsis databases [40]. In the molecular function category, $39 \%$ of the contigs were correlated to a GO term. When 
Table 3: Consensus sequences correlated to terms belonging to the "molecular function" categories of the Gene Ontology

\begin{tabular}{|c|c|c|c|c|c|c|}
\hline \multirow[t]{2}{*}{ Molecular functions } & \multicolumn{3}{|c|}{ Annotations including electronic annotations } & \multicolumn{3}{|c|}{ Annotations excluding electronic annotations } \\
\hline & $\begin{array}{l}\text { Number of } \\
\text { consensus } \\
\text { sequences }\end{array}$ & $\begin{array}{l}\% \text { of the number } \\
\text { of annotated } \\
\text { consensus } \\
\text { sequences }\end{array}$ & $\begin{array}{c}\% \text { of the total } \\
\text { number of } \\
\text { consensus } \\
\text { sequences }\end{array}$ & $\begin{array}{l}\text { Number of } \\
\text { consensus } \\
\text { sequences }\end{array}$ & $\begin{array}{l}\% \text { of the number } \\
\text { of annotated } \\
\text { consensus } \\
\text { sequences }\end{array}$ & $\begin{array}{c}\% \text { of the total } \\
\text { number of } \\
\text { consensus } \\
\text { sequences }\end{array}$ \\
\hline Triplet codon-amino acid adaptor activity & 0 & 0 & 0 & 0 & 0 & 0 \\
\hline Chaperone regulator activity & 0 & 0 & 0 & 0 & 0 & 0 \\
\hline Motor activity & 23 & 0.35 & 0.14 & 3 & 0.06 & 0,02 \\
\hline Enzyme regulator activity & 47 & 0.71 & 0.28 & 27 & 0.53 & 0.16 \\
\hline Nutrient reservoir activity & 50 & 0.76 & 0.30 & 4 & 0.08 & 0.02 \\
\hline Translation regulator activity & 70 & 1.06 & 0.42 & 59 & 1.16 & 0.36 \\
\hline Antioxidant activity & 73 & 1.10 & 0.44 & 52 & 1.02 & 0.31 \\
\hline Signal transducer activity & 77 & 1.16 & 0.46 & 33 & 0.65 & 0.2 \\
\hline Obsolete molecular function & 113 & 1.71 & 0.68 & 76 & 1.5 & 0.46 \\
\hline Transcription regulator activity & 118 & 1.78 & 0.71 & 73 & 1.44 & 0.44 \\
\hline Chaperone activity & 166 & 2.51 & 1 & 142 & 2.79 & 0.86 \\
\hline Structural molecule activity & 283 & 4.28 & 1.70 & 240 & 4.72 & 1.45 \\
\hline Transporter activity & 503 & 7.60 & 3.03 & 335 & 6.59 & 2.02 \\
\hline Binding & 1,248 & 18.87 & 7.52 & 741 & 14.6 & 4.46 \\
\hline Molecular function unknown & 1,340 & 20.26 & 8.07 & 1,340 & 26.4 & 8.07 \\
\hline Catalytic activity & 2,504 & 37.85 & 15.08 & 1,956 & 38.5 & 11.8 \\
\hline Total & 6,615 & 100 & 39.84 & 5,081 & 100 & 30.6 \\
\hline
\end{tabular}

the less reliable electronically inferred functional annotations were excluded, $30 \%$ of the ArboreaSet contigs were assigned molecular function annotations. The catalytic activity category included the largest number of sequences, followed by the proteins of unknown function. The classification we obtained was similar to that in the PGI5.0 database [41]. A significantly larger proportion of contigs were annotated in spruce than in pine, since we considered all of the blastx hits that met the alignment criteria, while the PGI5.0 annotations used only the top hit. Due to the restricted number of well-characterized conifer genes, correlating conifer sequences to Gene Ontology terms relies primarily on conservation with Angiosperms sequences (mainly Arabidopsis and rice). Therefore, the GO annotated contigs in spruce and in pine are the ones conserved with Angiosperms.

HMM searches against the PFAM database showed that the most abundant sequences in plant genomes were also among the most represented in the ArboreaSet (Figure 5). Highly comparable findings were made with the pine dataset (PGI5.0). A similar analysis conducted with the sugarcane SUCEST database indicated that the most abundantly represented molecular functions were largely overlapping between conifers and sugarcane [29].

\section{Families of putative transcription factors}

We identified putative transcription factors based upon the assignment of GO terms, as well as sequence comparison to PFAM domains and families $[37,38]$. The GO based annotation "transcription regulator activity" was assigned to 113 spruce sequences (including 40 assignments based upon automatic annotations) and the annotation "transcription factor activity" (GO:0003700) was assigned to 90 of the same consensus sequences. We also conducted HMM searches with the 41 PFAM profiles representing the plant transcription factors described in the Arabidopsis thaliana Transcription Factor Database (AtTFDB, from the Arabidopsis Gene Regulatory Information Server, AGRIS) [42] and identified 304 spruce transcripts (Table 4). Only 43 of these putative transcription factors were identified by both approaches. The combined total represented 388 putative transcription factors sequences. The most frequent sequence similarities were with C3HC4 zinc finger domain, WD, and AP2, respectively.

\section{Cell wall related genes}

Many of the libraries that we constructed were derived from secondary vascular tissues from stems or roots, or from whole stems or roots containing primary as well as secondary vascular regions. Therefore, we aimed to classify genes which encode proteins potentially involved in cell wall assembly. As a first step toward this goal, our collection of spruce transcripts was blasted against the sequences from the Cell Wall Navigator Database [43] [see Additional file 2], comprised of proteins involved in primary cell wall structure and assembly. In total, we 


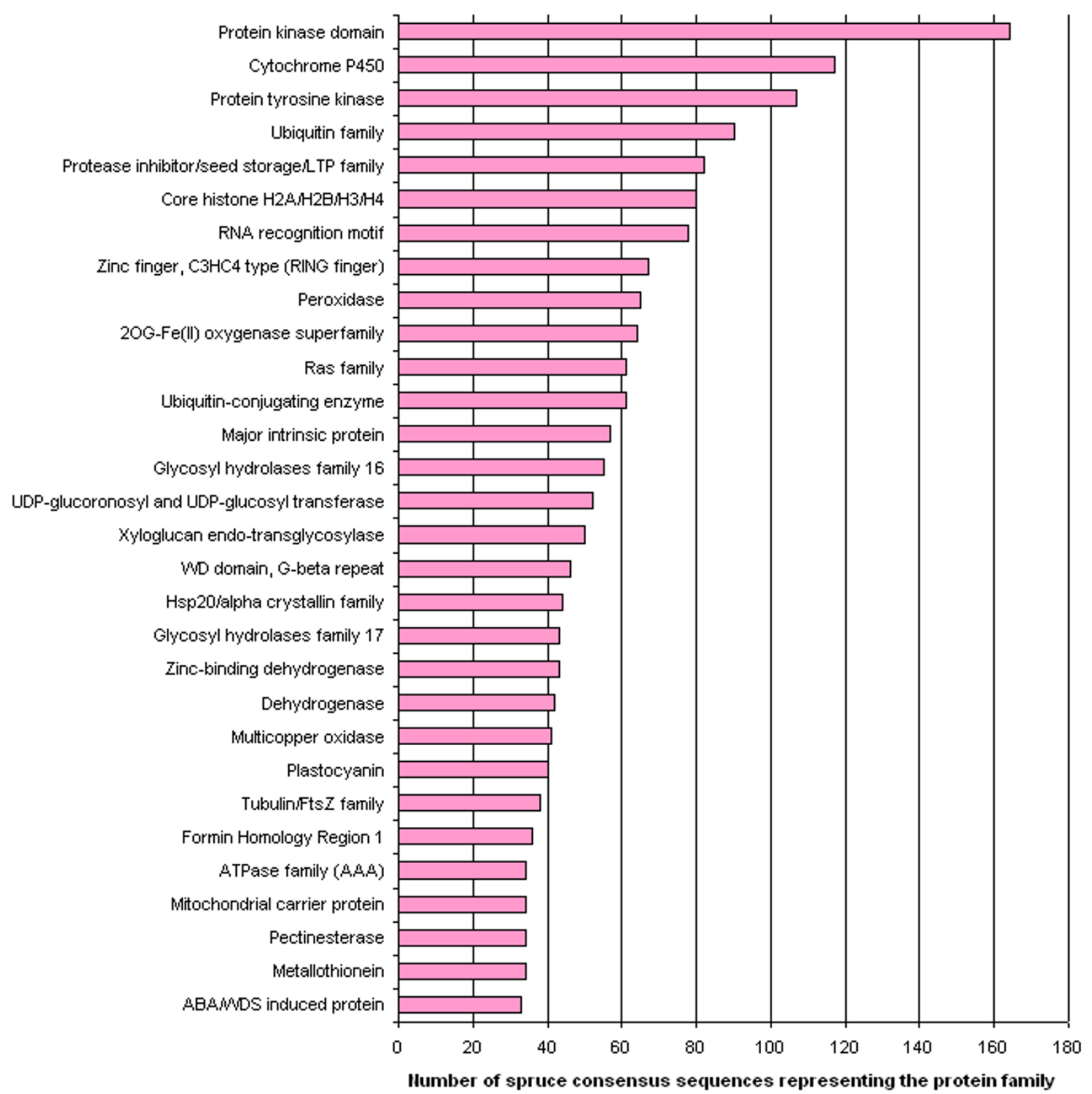

Figure 5

Protein families. Occurrence of the 30 most abundant protein families in the white spruce dataset identified by HMM searches with an e-value < I e- 10 against the PFAM database.

found that 708 spruce contigs were similar to sequences of cell wall related proteins, with nearly all of the subclasses represented. We also searched for genes encoding enzymes involved in the biosynthesis monolignol precursors based upon sequence similarity with the set identi- fied in Arabidopsis by Reas et al. [44], and identified 47 additional contigs (Supplemental data 2). 
Table 4: Identification of transcripts encoding putative regulatory proteins. Sequences were identified based on HMM searches suported by p-score < I e- 10 with PFAM profiles available for families of regulatory proteins. The PFAM accessions for which no homology was found in SpruceDB through HMM search were not reported.

\begin{tabular}{|c|c|c|}
\hline Protein family & PFAM accession & Number of spruce transcripts \\
\hline Zinc finger, C3HC4 type (RING finger) & PF00097 & 66 \\
\hline WD, G-beta repeat & PF00400 & 44 \\
\hline AP2 domain-B3 DNA binding domain & PF00847 & 19 \\
\hline HMG (high mobility group) box & PF00505 & 16 \\
\hline MADS Family - SRF-type transcription factor - K-box region & PF00319 & 14 \\
\hline MYB DNA-binding & PF00249 & 13 \\
\hline AUX/IAA & PF02309 & 12 \\
\hline Histone-like transcription factor (CBF/NF-Y) and archaeal histone & PF00808 & 11 \\
\hline PHD finger - CW-type Zinc Finger & PF00628 & 10 \\
\hline No apical meristem (NAM) protein & PF02365 & 10 \\
\hline GRAS Family & PF035I4 & 10 \\
\hline WRKY DNA-binding domain & PF03I06 & 9 \\
\hline NAC domain & PF01849 & 9 \\
\hline Homeobox domain & PF00046 & 8 \\
\hline bZIP transcription factor - bZIP Maf transcription factor-G-box binding protein MFMR & PF00I70 & 8 \\
\hline B-box zinc finger & PF00643 & 6 \\
\hline TUB Family & PFOII67 & 6 \\
\hline Helix-loop-helix DNA-binding domain - Myc amino-terminal region & PF000I0 & 5 \\
\hline KNOX2 domain & PF0379I & 3 \\
\hline LIM domain family - PET Domain & PF004I 2 & 5 \\
\hline Dof domain, zinc finger & PF0270I & 4 \\
\hline GATA zinc finger & PF00320 & 3 \\
\hline TCP family transcription factor & PF03634 & 2 \\
\hline CCAAT-HAP2 Family CCAAT-binding transcription factor (CBF-B/NF-YA) subunit B & PF02045 & 2 \\
\hline SBP (Sqamosa-promoter binding protein) floral development & PF03IIO & I \\
\hline HSF Family (Heat shock protein promoter binding) & PF00447 & I \\
\hline EIL Family ethylene insensitive 3 & PF04873 & I \\
\hline B3 DNA binding domain & PF02362 & I \\
\hline ARID/BRIGHT DNA binding domain - ELM2 domain & PF0I388 & I \\
\hline
\end{tabular}

Redundancy analysis suggests larger size of selected protein families in spruce compared to Angiosperms

It is not expected that Gymnosperm genomes will be sequenced in the foreseeable future, therefore we undertook a preliminary comparative analysis of protein families using the 14,471 spruce transcripts, to assess whether insights may be gained into the relative size of protein families in Gymnosperms and Angiosperms. We compared the occurrence of proteins in the ArboreaSet to that observed in the Arabidopsis genome (1,611 families) as well as in the rice genome (1,601 families) identified with HMM searches against the PFAM database. As might be expected from the partial coverage of the spruce genome, the vast majority of the protein families were represented by a larger number of sequences in the Arabidopsis and rice genomes than in ArboreaSet (Figure 6). However, several families gave twice as many hits in the ArboreaSet (67 and 58 families compared to Arabidopsis and rice, respectively) and a few families had at least 4 times more sequences ( 6 for Arabidopsis and 10 for rice, including 3 families for both). Some of these families encoded proteins that can be linked to the cell wall catabolism (PF01476), single carbon metabolism (S-adenosylmethionine synthetase PF02773), the cytoskeleton (Translationally Controlled Tumour Protein, TCTP family PF00838) or the cellular membrane (AWPM-19-like family PF05512). We verified that the size of the 4-fold larger families of spruce sequences was not inflated due to incomplete assembly of 3 ' and 5 ' reads. For two of the putatively larger families, we examined the protein and nucleic acid sequence diversity between the different consensus sequences in order to estimate the number of family members (results presented below).

\section{The cytoskeleton related TCTP family}

The translationally controlled tumour proteins (TCTPs) are anti-apoptotic proteins, named for their preferential synthesis in the early phase of some tumours [45]. They 

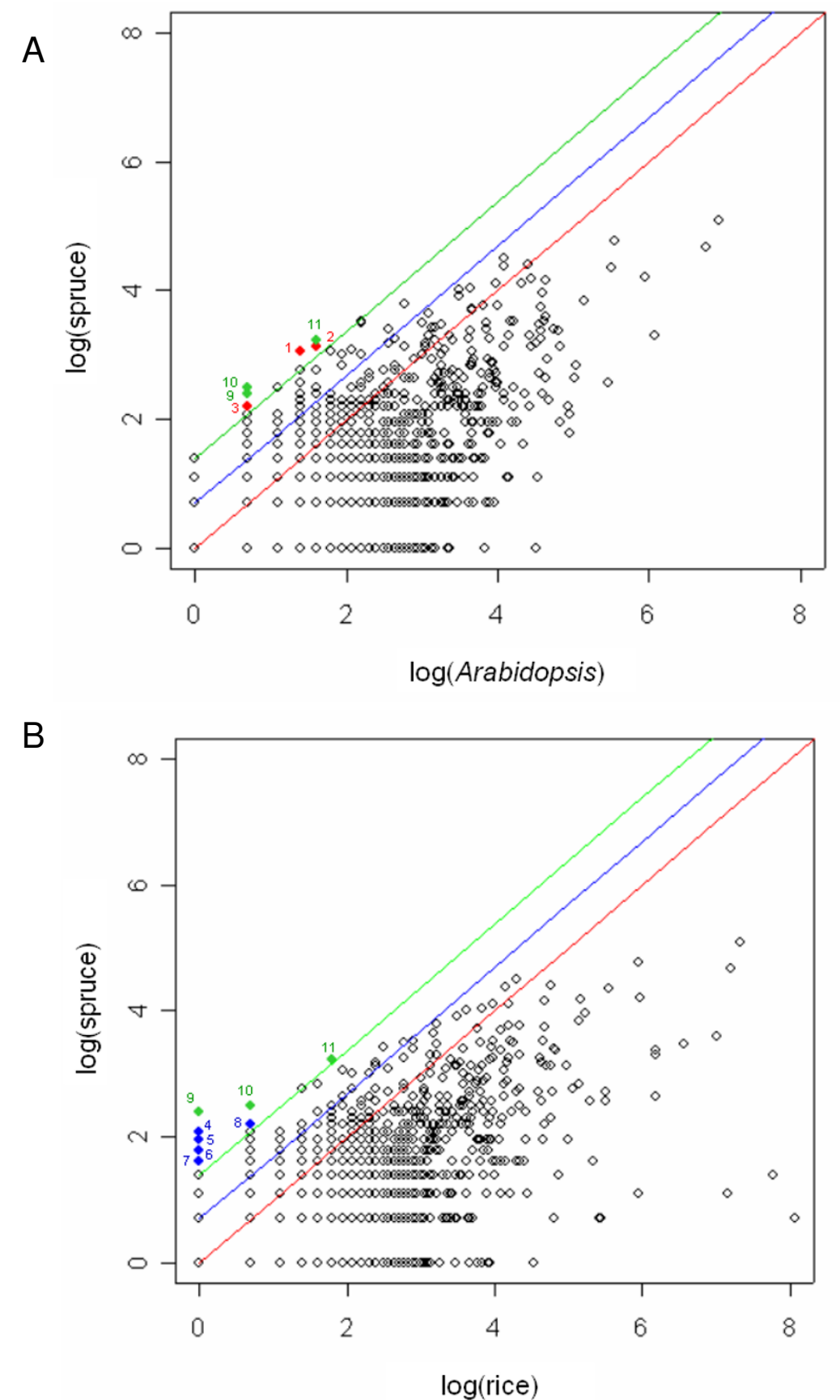

Figure 6

Number of spruce consensus sequences (identified by HMM searches against PFAM) relative to the size of the gene families in Arabidopsis (a) and rice (b). Each point represents a protein family detected by the HMM searches with $\mathrm{p}$-score $<$ le-10. Point coordinates are the number of genes found in the analysed Angiosperm genome $(x$ axis) and the number of contigs found in the spruce database ( $y$ axis), after a log transformation. The red, blue and green lines represent the ratios I:I, I:2, and I:4, respectively. Red points represent sequences found 4 times more in white spruce than in Arabidopsis: I. AWPM-19-like family [PF055 I2], 2. Chalcone and stilbene synthases, C-terminal domain [PF02797], 3. Phosphoenolpyruvate carboxykinase [PFO 293]. Blue points represent sequences found 4 times more in spruce than in rice : 4. Ribosomal protein S28e [PFOI 200], 5. Cyclin-dependent kinase regulatory subunit [PF0I I I I], 6. TIR domain [PF0 I 582], 7. Splicing factor 3B subunit 10 [PF07189], 8. Ribosomal Proteins L2, C-terminal domain [PF03947]. Green points represent sequences found 4 times more in spruce compared to both Arabidopsis and rice: 9. Translationally controlled tumour protein [PF00838], 10. S-adenosylL-homocysteine hydrolase [PF0522I], I I. S-adenosylmethionine synthetase, C-terminal domain [PF02773]. 
Table 5: Pairwise comparison of white spruce consensus sequences related to the translationally controlled tumour proteins (TCTP). Nucleic acid identities were determined using the Smith-Waterman algorithm (water) available in the EMBOSS suite [7I] in a I38 bp region of the 5' UTR immediately upstream of the first codon (ATG), (above the diagonal); and, along the complete sequence of the consensus sequences (under the diagonal). The diagonal shows the contig length.

\begin{tabular}{lccccc}
\hline & Sequence I0076 & Sequencel0707 & Sequence953I & Sequence7749 & Sequencel882 \\
\hline Sequencel0076 & 805 & $88 / 162(54.3 \%)$ & $54 / 84(64.3 \%)$ & $70 / 159(44.0 \%)$ & $83 / 144(57.6 \%)$ \\
Sequencel0707 & $761 / 890(85.5 \%)$ & 977 & $111 / 157(70.7 \%)$ & $71 / 147(48.3 \%)$ & $99 / 154(64.3 \%)$ \\
Sequence953I & $759 / 889(85.4 \%)$ & $925 / 1034(89.5 \%)$ & 1124 & $65 / 133(48.9 \%)$ & $101 / 159(63.5 \%)$ \\
Sequence7749 & $515 / 659(78.1 \%)$ & $548 / 736(74.5 \%)$ & $596 / 938(63.5 \%)$ & 945 & $73 / 147(49.7 \%)$ \\
Sequencel882 & $719 / 815(88.2 \%)$ & $742 / 823(90.2 \%)$ & $750 / 906(82.8 \%)$ & $523 / 687(76.1 \%)$ & 796 \\
\hline
\end{tabular}

are implicated in both cell growth and division and have been shown to bind to tubulin in the cytoskeleton. In plants, similar proteins were identified in alfafa [46] and Pharbitis mil [47].

The TCTP domain (accession : PF00838) was found in only two Arabidopsis sequences (At3g16640.1 and At3g05540.1) and one rice sequence (location in Gramene: LOC_Os11g43900.1). In contrast, there were 11 transcripts in the ArboreaSet that encompassed a highly conserved region of TCTPs and showed a high level of sequence conservation with Arabidopsis TCTPs (e.g. $70 \%$ a.a. identity for predicted sequence of Contig9531 and the Arabidopsis sequence gb|AAM66134.1). In total, 8 of the 11 spruce TCTP transcripts encompassed a putative complete coding sequence that overlapped with the Arabidopsis proteins. Pairwise nucleic acid sequence comparisons of the 11 spruce transcripts were used to identify 5 distinct sequence groups, likely representing a minimum of 5 different genes (Table 5). Based upon these data, the TCTP family provided an example of putative differential protein family size between spruce and the Angiosperms represented by rice and Arabidopsis.

\section{The SAMS family}

Sequences encoding S-adenosylmethionine synthetases (SAMS), a family of enzymes involved in single carbon metabolism and in lignin precursor biosynthesis [48] were represented by 24 consensus sequences encompassing at least seven spruce genes (Table 6). It has been reported that sams genes belong to small gene families in other plant species [49-53]. In Arabidopsis, four sams genes were identified. In rice, three sequences encoding complete proteins of 396 amino acids were found, as well as two sequences encoding truncated proteins of 164 amino acids [54].

We analyzed the 8 spruce sams transcripts that encompassed complete protein coding sequences averaging 393 amino acids in length. The predicted proteins were very highly conserved with Angiosperm SAMS. For example, the Arabidopsis SAMS2 protein (locus At4g01850) had a similarity of $88 \%$ (345/390a.a) and $90 \%$ (354/390 a.a) with the predicted proteins from the spruce contigs 10446 and 10482, respectively. Pairwise comparisons of the spruce coding sequences showed they are highly conserved, yet they could be divided into seven groups of sequences with $66.3 \%$ to $91.3 \%$ identity (Table 6). We also analyzed the nucleic acid sequence of their 96 bp 3' UTR and found significant variability between groups, with sequence identities varying from $42.5 \%$ to $70.7 \%$ (Table 6). These results provided a strong indication that these putative sams transcripts represented 7 distinct genes. Protein and nucleic acid sequence comparisons supported the hypothesis that the SAMS proteins form a larger family in the spruce genome than in Arabidopsis and rice. In rice, the presence of two pseudogenes indicated that protein family expansions through duplication events have been followed by gene loss during the evolution. Two sams genes were described in Pinus contorta [55]; however, large-scale EST sequencing in Pinus taeda [56] identified 16 consensus sequences, suggesting that the relatively large family size of SAMS in spruce may also apply to pine and other Gymnosperm genomes.

\section{Development of Spruce DB}

The relational database, SpruceDB, was created to allow complex queries into the spruce ESTs, assembled consensus sequences and results of similarity analyses. The database can be accessed via web browser [28]. Web-based tools provide facilities for exploration of this information resource. The ESTs or contigs can be retrieved based on library composition and sequence similarities. Web links from the database query pages retrieve the actual EST and contig sequences from the Biodata web pages [56].

\section{Structure and data sources}

The database schema for SpruceDB is identical to the one successfully used by the MtDB2.0 database for Medicago truncatula EST data [57]. SpruceDB is hosted on a Sun V880 server running the Oracle $8 \mathrm{i}$ Database Management System. The data sources and core tables for the database 
Table 6: Pairwise comparison of white spruce consensus sequences related to the S-adenosylmethionine synthetase (SAMS). Nucleic acid identities were determined using the Smith-Waterman algorithm (water) available in the EMBOSS suite [7I] in a 99 bp region of the 3' UTR immediately downstream the stop codon (above the diagonal) and along the complete sequence of the consensus sequences (under the diagonal). The diagonal shows the contig length.

\begin{tabular}{|c|c|c|c|c|c|c|c|}
\hline & Sequence 10446 & Sequence 10482 & Sequence 10630 & Sequence 10683 & Sequence 10828 & Sequence 8600 & Sequence 9676 \\
\hline Sequence I0446 & 1677 & $46 / 97$ (47.4\%) & $48 / 113$ (42.5\%) & $51 / 117$ (43.6\%) & $45 / 85$ (52.9\%) & $85 / 106$ (80.2\%) & $44 / 98$ (44.9\%) \\
\hline Sequence 10482 & $1096 / 1607$ (68.2\%) & 1467 & $54 / 78(69.2 \%)$ & 65/92 (70.7\%) & $50 / 84(59.5 \%)$ & $49 / 114(43 \%)$ & $45 / 96(46.9 \%)$ \\
\hline Sequence 10630 & || $26 /|64|$ (68.6\%) & I343/I557 (86.3\%) & 1540 & $69 / 113(61.1 \%)$ & $48 / 78$ (61.5\%) & $47 / 95(49.5 \%)$ & $55 / 111(49.5 \%)$ \\
\hline Sequence 10683 & || $43 /|7| \mid(66.8 \%)$ & $1342 /|52|(88.2 \%)$ & |357/| 582 (85.8\%) & $|53|$ & $49 / 103$ (47.6\%) & $58 / 116(50 \%)$ & $46 / 117$ (39.3\%) \\
\hline Sequence 10828 & $1202 / 18 \mid 4(66.3 \%)$ & $1262 / 1534$ (82.3\%) & $1343 / 17 \mid 4$ (78.4\%) & I306/I604 (8I.4\%) & 1679 & $49 / 95$ (51.6\%) & $49 / 109(45 \%)$ \\
\hline Sequence8600 & $1349 / 169 \mid$ (79.8\%) & $1058 / 1536$ (68.9\%) & $1089 / 1532$ (7I.1\%) & $1092 / 1583(69 \%)$ & $1120 / 1656$ (67.6\%) & 1476 & $4|/ 7|(57.7 \%)$ \\
\hline Sequence 9676 & $1025 / 1418$ (72.3\%) & $1314 / 1459(90.1 \%)$ & $1276 / 1397$ (91.3\%) & $|26| /|38|$ (91.3\%) & $1179 / 1369$ (86.1\%) & $1026 / 1462$ (70.2\%) & 1356 \\
\hline
\end{tabular}

are illustrated in Figure 7. Sequence trimming methods and assembly parameters for Phrap are described in the Methods section. Information about ESTs and consensus sequences assembled with Phrap is extracted from flat files and loaded into the core tables Read, Contig and Contig_Element. These tables store the sequences and lengths, base qualities, EST libraries, clone names, and assembly name. Several tables store pre-computed blast hit information from blast similarity analyses against several target databases: UniRef100 peptides, Arabidopsis proteins, SpruceDB itself. Data fields include analysis program, target name, hit identifier, e-value, identities and taxonomy identifier for each hit. All blast hits with evalues less than 0.01 are loaded into the database.

\section{Interface}

The web pages used to query the database allow retrieval of ESTs or contigs based on the cDNA libraries and blast hits (Figure 8). Since the nine query pages consist of check boxes and pull-down menus, no programming or knowledge of SQL is required, yet users can generate complex queries. Query 1 retrieves consensus sequences that have blast hits containing user-specified keywords or accession numbers. Queries 2-7 are library filter queries which retrieve ESTs or consensus sequences containing "any of", "all of", or "only" ESTs from user-specified cDNA libraries. Queries 3-7 contain taxonomy and e-value filters which retrieve sequences that have blast hits to organisms from specified taxa such as "all pines", "all poplars", or Arabidopsis. Query 5 combines the library, taxonomy and e-value filters in a single web page. Query 8 retrieves EST sequences using different names (aliases). Query 9 compares consensus sequences between different assemblies.

\section{Conclusion}

In this report, we described a new conifer EST resource derived from 49,101 high quality 5' and 3' reads that were assembled to produce 16,578 consensus sequences averaging 797 nucleotides in length, and representing
14,471 different "transcripts". We estimated the sequencing redundancy at $39 \%$ based on the number of consensus sequences represented by more than one cDNA clone. Comparison of the spruce sequences to public sequence datasets from Angiosperms and pine showed that approximately $70 \%$ of the sequences had similarity with Arabidopsis, rice or poplar sequences, but $84 \%$ matched a pine sequence. The majority of the sequences that did not give a match in pine did not produce a match with any of the Angiosperms either. We used a variety of approaches based on sequence similarity searches to assigned putative functions to the ArboreaSet sequences, including blast searches against general and specialized datasets, GO term assignation, HMM searches against PFAM protein families and domains. These analyses were used for the systematic identification of diverse putative transcription factors, cell wall related enzymes and structural proteins, and revealed a few protein families that are thought to be larger in spruce than in the well-characterized genomes of Arabidopsis and rice.

These comprehensive analyses to enable the annotation of spruce sequences provide critical information to help identify target genes for functional analysis and association studies. Studies are now being planned based on these data to search for DNA polymorphisms underlying the extensive phenotypic variation which occurs in natural and breeding populations. These studies will focus on sequences encoding proteins relevant for adaptation, growth and wood formation for large-scale SNP discovery and genotyping required for association studies and gene mapping. It is therefore essential that we develop databases of annotated coding sequences so that we may rapidly identify and screen the most suitable targets. As a first step toward this goal, the relational database SpruceDB was created to allow complex queries into the spruce ESTs, assembled consensus sequences and results of similarity analyses. By using this EST resource, we have also developed a low redundancy cDNA microarray comprised of 


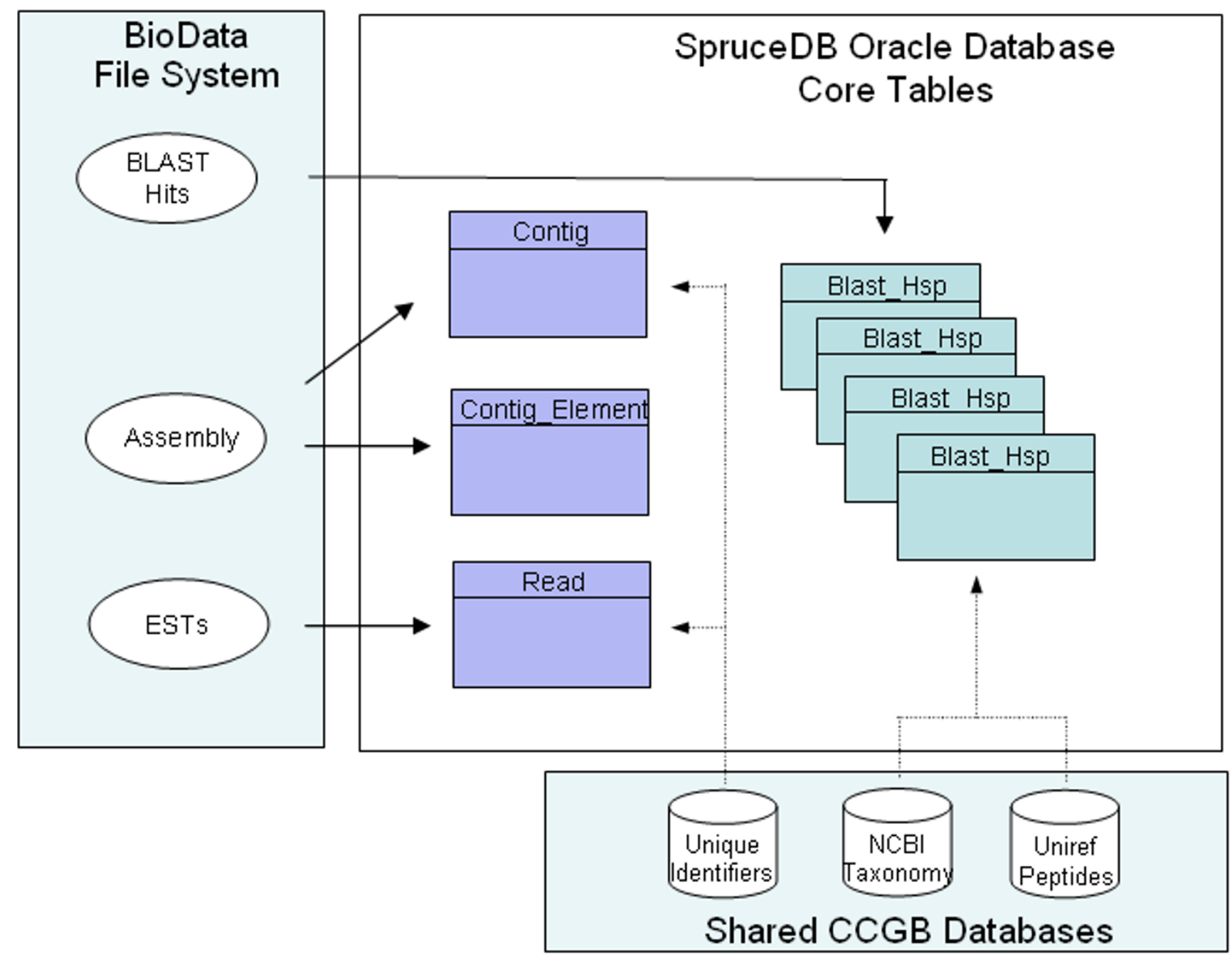

Figure 7

SpruceDB core tables and data sources. Data from flat files on ESTs, Assemblies and blast hits is loaded into the core tables Read, Contig, Contig_Element and Blast_Hsp. Additional information on taxonomy identifiers and UnirefI 00 peptides is obtained from shared databases.

9,690 sequences, which, in combination with multiple sequence annotations, will be a powerful tool to investigate transcriptome modulation in spruces and conifers.

\section{Methods}

\section{Plant material}

All of the libraries were comprised of a single organ or tissue, and the majority of libraries were developed by pooling samples collected at different points along a time course, along the diurnal cycle, at several stages of differentiation or from different treatments (Supplemental data 2 and [58]). Treatments known to affect plant physiology were applied to saplings (young trees) aiming to stimulate different transcript profiles. These treatments included $\mathrm{N}$ and $\mathrm{P}$ fertilization as well as stem girdling. Three libraries were made from whole root systems of very young spruce seedlings, produced through tissue culture, grown in sterile growth media. Most of the libraries were derived from one genotype (pg-653), however four libraries were comprised of two or more genotypes. The secondary xylem collected from saplings (library GQ007) was comprised of the entire sampling of woody tissues collected from seedlings; however, only the differentiating partly-lignified secondary xylem was collected from mature trees as previously described [16]. The secondary xylem tissues were collected by first gently separating the 


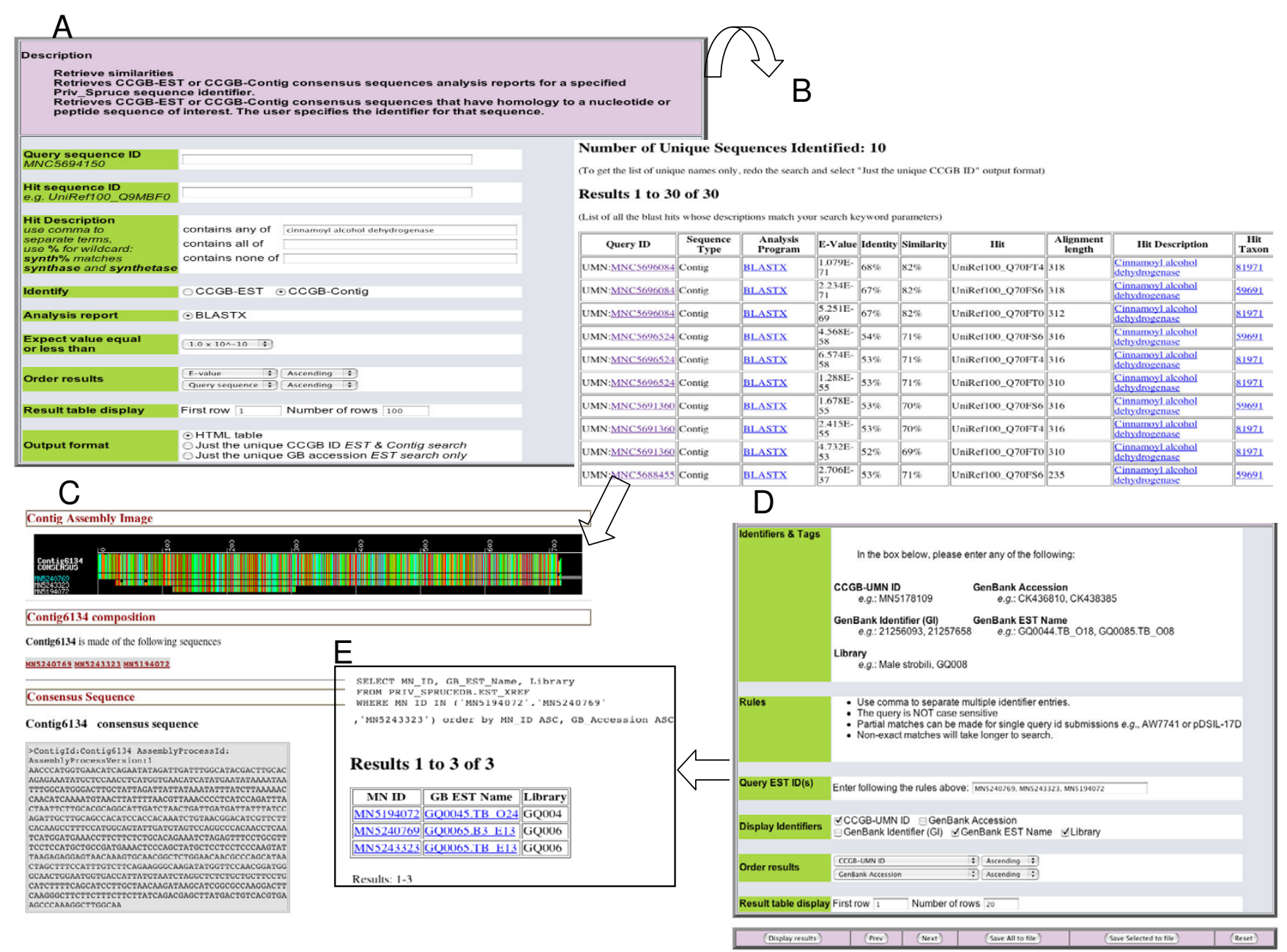

\section{Figure 8}

Examples of the interface of the SpruceDB database. A) Use of Query I to search for contigs matching "cinnamoyl alcohol dehydrogenase" among the blastx results loaded in the database. B) Display of the results indicating alignment parameters (alignment length, similarity and identity level). C) BioDATA page linked to by clicking on MNC5693 I53 in Query I

results. The upper figure illustrates the alignment of the members of the contigs in a color coded manner. Read names written in blue and white color refer to 5'and 3'reads, respectively. D) Query 8 allowing to retrieve sequence aliases and library names for specified MN_Ids. E) Query 8 results showing libraries GQ004 and GQ006.

bark from the underlying wood and scraping the soft tissues inward of the cambial area. The secondary phloem of mature trees was collected by gently scrapping the inner surface of the bark with a scalpel blade. All tissue samples were frozen in liquid nitrogen and then stored at $-80^{\circ} \mathrm{C}$ until RNA extraction immediately upon removal from the tree, seedling or tissue culture vessel.

\section{cDNA library construction, quality controls and high- throughput sequencing}

We began the construction of each library with 1000 micrograms of total RNA or more, isolated using the method of Chang et al. [59]. Poly A+ RNA was isolated using the PolyATtract mRNA Isolation System (Promega, San Luis Obispo, CA, USA). The polyA+ RNA was treated with methylmercury hydroxide according to the manufacturer's instruction (Stratagene, La Jolla, CA, USA) to relax its secondary structure. Double-stranded cDNA was synthesized from 5 micrograms $(\mu \mathrm{g})$ of poly A+ selected RNA using a pBluescript II SK (+) XR cDNA Library Construction kit (Stratagene, La Jolla, CA, USA). The reverse transcription step was carried out with either Superscript II or Superscript III and StrataScript (Invitrogen, Burlington, ON, Canada; Stratagene, La Jolla, CA, USA) as described 
in the manufacturer's instructions. The double stranded cDNAs were fractionated using the Drip column method (Stratagene, La Jolla, CA, USA) or by agarose gel electrophoresis on NuSieve GTG Agarose (Mendel, Guelph, ON, Canada) followed by selective elution of particular-sized cDNA molecules by ß-Agarase I digests according to the manufacturer's instruction (NEB, Pickering, ON, Canada). The size distribution of the resulting double cDNA synthesized in second-strand fractions was visualized by electrophoresis on a $1.4 \%$ alkaline agarose gel [60]. The fractions of $600 \mathrm{pb}$ to $1.2 \mathrm{~kb}$ and above $1.2 \mathrm{~kb}$ were selected, pooled, directionally ligated into the EcoRI and XhoI restriction sites of the pBluescript II SK (+) XR vector (Stratagene, La Jolla, CA, USA), and transformed into E.coli DH10B competent cells (Invitrogen, Burlington, ON, Canada) by electroporation. The library quality assessment used test ligations to determine library titer. We also estimated the proportion of empty vectors as based upon the proportion of blue to white colonies grown on LB agar supplemented with X-GAL/IPTG (Table 1 ). The average CDNA insert size was determined by PCR screening of 48 to 96 random white colonies (assumed contain plasmids with inserts) per test ligation, followed by determination of the PCR product size by gel electrophoresis. The highest quality libraries were those estimated to have the highest proportion of inserts above 1.6 $\mathrm{Kb}$ (Table 1). High-throughput sequencing of libraries was completed using standard methodsas described by Yang et al. [61].

\section{EST processing and assembly}

Sequence traces from the spruce EST libraries were analyzed with the Phred base calling software (version $0.980904)$ to generate raw sequences [62]. Peaks with Phred quality values less than 20 were considered to be ambiguous and were assigned base N. Quality trimming and vector filtering (with polyA/polyT removal, as appropriate) were done. Processed sequences were then assembled using the base quality files and Phrap (version 0.990329) [63]. Phrap contigs were evaluated for chimeric sequences, and reassembled after removing chimeric reads. The Phrap assembly parameters used were minmatch 50 and minscore 100 . Only reads with at least 100 nt of sequence with a quality score above 20 were assembled. EST sequences were submitted to dbEST at the National Center for Biotechnology Information [64] under accession numbers : [Genbank:CK434215CK445169] and [Genbank:CO472624-CO490610].

\section{Quality control of consensus sequences}

The quality control of resulting consensus sequences used a system developed at the CCGB. This system uses information that is included in the contig ace file generated by Phrap. From the ace file, several important characteristics of a consensus sequence and its member sequences can be determined. The first characteristic used in this process is the "shape" of the consensus sequence, or how the assembled reads overlap each other. This can be thought of as the profile of the consensus sequence member distribution. Consensus sequences are classified as being of block, staircase, or dumbell shape. Contigs with a dumbell shape are candidates for additional evaluation.

Reads within a dumbell shaped contig are evaluated for their similarity to the consensus sequence of the contig. Phrap provides information on the quality regions of assembled sequences, which is used for this step. If the high quality region of the read (as defined by the Phrap ace file) has less than 95\% consistency with the consensus sequence of the contig, or has more than 5 mismatched bases relative to the consensus, the read is flagged as a suspected chimera, provided it also shows evidence of either a polyA or polyT region.

The final step of the quality control process is to examine the flagged reads visually to find chimeric qualities. Chimeric reads are selected and removed based on their similarity to the consensus sequence and to the individual reads in the contig. A chimeric read may also be indicated if blast hits to different proteins are found to be adjacent in the read. The process of chimera detection and removal is often repeated numerous times before arriving at a finished assembly.

\section{Sequence comparison and assignment into functional categories}

Similarity searches were performed with the tblastx or blastx programs [65] against the TIGR Gene Indices available for Arabidopsis (AGI11), rice (OGI16) and pine (PGI5.0), retrieved from the TIGR web site [66] and against one Cycas EST assembly [67], retrieved from Sputnik web site [68]. Blast searches were conducted against several databases: the NCBI non redundant database (nr), the Uniref100 peptides set [39], and the Cell Wall Navigator Database [43]. HMM searches were conducted with the PFAM profiles (PFAM release16.0) with the local alignment setting since the spruce consensus sequences are fragmentary sequences. The Arabidopsis and rice coding sequences were downloaded from the TAIR web site [69] and the Rice Genome Annotation Database from TIGR [70], respectively.

To correlate the spruce consensus sequences to a Gene Ontology (GO) molecular function term, the annotations of homologous Uniref100 and Arabidopsis proteins were analysed. For each spruce consensus sequence, the blastx hits with a minimum similarity value of 0.75 and a minimum coverage of 0.5 were used in the GO assignment procedure. Similarity was defined as hsp positive/hsp alignment length (hsp : high scoring pair). Coverage was 
defined as the high scoring pair alignment length $\times 3 /$ query length. Among the retained hits, whenever a spruce sequence matched a protein with an associated GO term, this term was transferred to the spruce consensus sequence. Two GO annotation lists were completed: one including evidence codes Inferred from Electronic Annotation (IEA) evidence codes and one excluding IEA evidence.

\section{Authors' contributions}

$\mathrm{NP}$, coordination of bioinformatics activities, data analysis, preparation of the manuscript; CP, LP, JC, JEJ, ER, sequence processing, assembly and annotation, web publishing and database development; MJM, JC, ASé, plant material production, library synthesis, and evaluation; $\mathrm{EN}, \mathrm{CGC}$, protein family sequence analyses; $\mathrm{YB}, \mathrm{SB}, \mathrm{GY}$, JS, ASi, RH, MM, high-throughput EST sequencing and quality assurance; $\mathrm{CP}, \mathrm{JB}$, preparation of manuscript; JM, overall project supervision, preparation of manuscript.

\section{Additional material}

\section{Additional File 1}

Description of tissues used for cDNA library synthesis: genotype, treatments (type, level and duration), organ, tissue and developmental stage. Click here for file

[http://www.biomedcentral.com/content/supplementary/14712164-6-144-S1.doc]

\section{Additional File 2}

Annotation of proteins related to the cell wall based on similarities with sequences from the Cell Wall Navigator Database [44]and lignin biosynthesis enzymes [45]. Spruce homologs were identified by tblastx searches with e-value $<1 e-10$.

Click here for file

[http://www.biomedcentral.com/content/supplementary/14712164-6-144-S2.doc]

\section{Acknowledgements}

Funding for this work was provided by Genome Canada and Genome Québec to J.M., A. Sé. and J.B. for the project Arborea. We acknowledge the "Centre de Bioinformatique de I'Université Laval" for bioinformatics support. We also acknowledge H. Bérubé, S. Blais, C. Delisle, S. Forest, V. Roy for their technical assistance and B. Pelgas for her reading of the draft.

\section{References}

I. Ahuja MR: Recent advances in molecular genetics of forest trees. Euphytica 200 I, I 21: 173-195.

2. Dhillon SS: DNA in tree species. In Cell and Tissue Culture in Forestry Volume I. Edited by: Bonga JM, Durzan DJ. Martinus Nijhoff Publishers, Dordrecht; 1987:298-313.

3. Wakamiya I, Newton RJ, Price JS: Genome size and environmental factors in the genus Pinus. Am J Bot 1993, 80:1235-124I.

4. Rake AW, Miksche JP, Hall RB, Hanson KM: DNA reassociation kinetics for four conifers. Can J Genet Cytol 1980, 22:69-79.

5. Ohri D, Khoshoo TN: Genome size in gymnosperms. Plant Syst Evol 1986, 153:119-132.

6. Murray BG: Nuclear DNA amounts in gymnosperms. Ann Bot 1998:3-15.
7. Quackenbush J, Cho J, Lee D, Liang F, Holt I, Karamycheva S, Parvizi B, Pertea G, Sultana R, White J: The TIGR Gene Indices: analysis of gene transcript sequences in highly sampled eukaryotic species. Nucleic Acids Res 200I, 29:159-164.

8. Kirst M, Johnson AF, Baucom C, Ulrich E, Hubbard K, Staggs R, Paule C, Retzel E, Whetten R, Sederoff R: Apparent homology of expressed genes from wood-forming tissues of loblolly pine (Pinus taeda L.) with Arabidopsis thaliana. Proc Natl Acad Sci USA 2003, 100:7383-7388.

9. Pavy N, Laroche J, Bousquet J, Mackay J: Large-scale statistical analysis of secondary xylem ESTs in pine. Plant Mol Biol 2005, 57:203-224.

10. Guillet-Claude C, Isabel N, Pelgas B, Bousquet J: The evolutionary implications of knox-I gene duplications in conifers: correlated evidence from phylogeny, gene mapping, and analysis of functional divergence. Mol Biol Evol 2004, $21: 2232-2245$.

II. Allona I, Quinn M, Shoop E, Swope K, St Cyr S, Carlis J, Riedl J, Retzel $E$, Campbell M, Sederoff R, Whetten RW: Analysis of xylem formation in pine by cDNA sequencing. Proc Natl Acad Sci USA 1998, 95:9693-9698.

12. Dendrome project [http://dendrome.ucdavis.edu/dfgp/ about.html]

13. Treenomix project [http://www.treenomix.com]

14. Dubos C, Plomion C: Identification of water-deficit responsive genes in maritime pine (Pinus pinaster Ait.) roots. Plant Mol Biol 2003, 5 I:249-262.

15. Le Provost G, Paiva J, Pot D, Brach J, Plomion C: Seasonal variation in transcript accumulation in wood-forming tissues of maritime pine (Pinus pinaster Ait.) with emphasis on a cell wall glycine-rich protein. Planta 2003, 21 7:820-830.

16. Egertsdotter U, van Zyl LM, MacKay J, Peter G, Kirst M, Clark C, Whetten R, Sederoff R: Gene expression during formation of earlywood and latewood in loblolly pine: expression profiles of 350 genes. Plant Biol 2004, 6:654-663.

17. van Zyl L, von Arnold S, Bozhkov P, Chen Y, Egertsdotter U, MacKay J, Sederoff R, Shen J, Zelena L, Clapham D: Heterologous array analysis in Pinaceae: Hybridization of high density arrays of Pinus taeda cDNA with cDNA from needles and embryogenic cultures of $P$. taeda, $P$. sylvestris or Picea abies. Function Compar Genomics 2002, 3:306-3I8.

18. Stasolla C, Belmonte MF, van ZyI L, Craig DL, Liu W, Yeung EC, Sederoff $R$ : The effect of reduced glutathione on morphology and gene expression of white spruce (Picea glauca) somatic embryos. J Exp Bot 2004, 55:695-709.

19. Hertzberg M, Aspeborg H, Schrader J, Andersson A, Erlandsson R, Blomqvist K, Bhalerao R, Uhlen M, Teeri TT, Lundeberg J, Sundberg B, Nilsson P, Sandberg G: A transcriptional roadmap to wood formation. Proc Natl Acad Sci USA 200I, 98: I 4732-I 4737.

20. Yang J, Park S, Kamdem DP, Keathley DE, Retzel E, Paule C, Kapur V, Han KH: Novel gene expression profiles define the metabolic and physiological processes characteristic of wood and its extractive formation in a hardwood tree species, Robinia pseudoacacia. Plant Mol Biol 2003, 52:935-956.

21. Paux E, Tamasloukht M, Ladouce N, Sivadon P, Grima-Pettenati J: Identification of genes preferentially expressed during wood formation in Eucalyptus. Plant Mol Biol 2004, 55:263-280.

22. Canadian Council of Forest Ministers [http://nfdp.ccfm.org/]

23. Florin $\mathrm{R}$ : The distribution of conifer and taxad genera in time and space. Acta Horti Bergiani 1963, 20:121-312.

24. Bouillé $M$, Bousquet J: Trans-species shared polymorphisms at orthologous nuclear gene loci among distant species in the conifer Picea (Pinaceae): Implications for the long-term maintenance of genetic diversity in trees. Am J Bot 2005, 92:63-73.

25. Pelgas $B$, Bousquet J, Beauseigle $\mathrm{S}$, Isabel $\mathrm{N}$ : A composite linkage map from two crosses for the species complex Picea mariana [Mill.] B.S.P x Picea rubens (Sarg.) and analysis of synteny with other Pinaceae. Theor Applied Genetics 2005 in press.

26. Neale DB, Savolainen O: Association genetics of complex traits in conifers. Trends Plant Sci 2004, 9:325-330.

27. Gene Ontology Consortium: Creating the gene ontology resource: design and implementation. Genome Res 200I, I I: I 425-I 433.

28. SpruceDB [http://ccgb.umn.edu/Pub SpruceDB/]

29. Vettore AL, da Silva FR, Kemper EL, Souza GM, da Silva AM, Ferro MI, Henrique-Silva F, Giglioti EA, Lemos MV, Coutinho LL, Nobrega MP, 
Carrer H, Franca SC, Bacci Junior M, Goldman MH, Gomes SL, Nunes LR, Camargo LE, Siqueira WJ, Van Sluys MA, Thiemann OH, Kuramae EE, Santelli RV, Marino CL, Targon ML, Ferro JA, Silveira HC, Marin DC, Lemos EG, Monteiro-Vitorello CB, Tambor JH, Carraro DM, Roberto PG, Martins VG, Goldman GH, de Oliveira RC, Truffi D, Colombo CA, Rossi M, de Araujo PG, Sculaccio SA, Angella A, Lima MM, de Rosa Junior VE, Siviero F, Coscrato VE, Machado MA, Grivet L, Di Mauro SM, Nobrega FG, Menck CF, Braga MD, Telles GP, Cara FA, Pedrosa G, Meidanis J, Arruda P: Analysis and functional annotation of an expressed sequence tag collection for tropical crop sugarcane. Genome Res 2003, I3:2725-2735.

30. Forment J, Gadea J, Huerta L, Abizanda L, Agusti J, Alamar S, Alos E, Andres F, Arribas R, Beltran JP, Berbel A, Blazquez MA, Brumos J, Canas LA, Cercos M, Colmenero-Flores JM, Conesa A, Estables B, Gandia M, Garcia-Martinez JL, Gimeno J, Gisbert A, Gomez G, Gonzalez-Candelas L, Granell A, Guerri J, Lafuente MT, Madueno F, Marcos JF, Marques MC, Martinez F, Martinez-Godoy MA, Miralles S, Moreno P, Navarro L, Pallas V, Perez-Amador MA, Perez-Valle J, Pons C, Rodrigo I, Rodriguez PL, Royo C, Serrano R, Soler G, Tadeo F, Talon M, Terol J, Trenor M, Vaello L, Vicente O, Vidal Ch, Zacarias L, Conejero V: Development of a citrus genome-wide EST collection and CDNA microarray as resources for genomic studies. Plant Mol Biol 2005, 57:375-39l.

31. Kawai J, Shinagawa A, Shibata K, Yoshino M, Itoh M, Ishii Y, Arakawa T, Hara A, Fukunishi Y, Konno H, Adachi J, Fukuda S, Aizawa K, Izawa M, Nishi K, Kiyosawa H, Kondo S, Yamanaka I, Saito T, Okazaki Y, Gojobori T, Bono H, Kasukawa T, Saito R, Kadota K, Matsuda H, Ashburner M, Batalov S, Casavant T, Fleischmann W, Gaasterland T, Gissi C, King B, Kochiwa H, Kuehl P, Lewis S, Matsuo Y, Nikaido I, Pesole G, Quackenbush J, Schriml LM, Staubli F, Suzuki R, Tomita M, Wagner L, Washio T, Sakai K, Okido T, Furuno M, Aono H, Baldarelli R, Barsh G, Blake J, Boffelli D, Bojunga N, Carninci P, de Bonaldo MF, Brownstein MJ, Bult C, Fletcher C, Fujita M, Gariboldi M, Gustincich S, Hill D, Hofmann M, Hume DA, Kamiya M, Lee NH, Lyons P, Marchionn L, Mashima J, Mazzarelli J, Mombaerts P, Nordone P, Ring B, Ringwald M, Rodriguez I, Sakamoto N, Sasaki H, Sato K, Schonbach C, Seya T, Shibata Y, Storch KF, Suzuki H, Toyo-oka K, Wang KH, Weitz C, Whittaker C, Wilming L, Wynshaw-Boris A, Yoshida K, Hasegawa Y Kawaji H, Kohtsuki S, Hayashizaki Y, RIKEN Genome Exploration Research Group Phase II Team and the FANTOM Consortium: Functional annotation of a full-length mouse cDNA collection. Nature 200I, 409:685-690.

32. Whitfield Ch.W, Band MR, Bonaldo MF, Kumar ChG, Liu L, Pardinas $J R$, Robertson HM, Soares MB, Robinson GE: Annotated expressed sequence tags and cDNA microarrays for studies of brain and behavior in the honey bee. Genome Res 2002, 1 2:555-566.

33. Brown GR, Gill GP, Kuntz RJ, Langley CH, Neale DB: Nucleotide diversity and linkage disequilibrium in loblolly pine. Proc Natl Acad Sci USA 2004, I01: 15255-15260.

34. Pot D, McMillan L, Echt C, Le Provost G, Garnier-Géré P, Cato S, Plomion $C$ : Nucleotide variation in genes involved in wood formation in two pine species. New Phytologist 2005, 167:101-1/2.

35. Garcia-Gil MR, Mikkonen M, Savolainen O: Nucleotide diversity at two phytochrome loci along a latitudinal cline in Pinus sylvestris. Mol Ecol 2003, 12:1 | 95-1206.

36. Crow JA: Diogenes - Reliable prediction of protein-encoding regions in short genomic sequences. 2005 [http://analy sis.ccgb.umn.edu/diogenes].

37. PFAM database [http://www.sanger.ac.uk/Software/Pfam/]

38. Bateman A, Coin L, Durbin R, Finn RD, Hollich V, Griffiths-Jones S, Khanna A, Marshall M, Moxon S, Sonnhammer EL, Studholme DJ, Yeats C, Eddy SR: The Pfam Protein Families Database. Nucleic Acids Res 2004:DI38-DI4I.

39. Bairoch A, Apweiler R, Wu CH, Barker WC, Boeckmann B, Ferro S, Gasteiger E, Huang H, Lopez R, Magrane M, Martin MJ, Natale DA, O'Donovan C, Redaschi N, Yeh LL: The Universal Protein Resource (UniProt). Nucleic Acids Res 2005:DI54-DI59.

40. Rhee SY, Beavis W, Berardini TZ, Chen G, Dixon D, Doyle A, GarciaHernandez M, Huala E, Lander G, Montoya M, Miller N, Mueller LA, Mundodi S, Reiser L, Tacklind J, Weems DC, Wu Y, Xu I, Yoo D, Yoon J, Zhang P: The Arabidopsis Information Resource (TAIR): a model organism database providing a centralized, curated gateway to Arabidopsis biology, research materials and community. Nucleic Acids Res 2003, 31:224-228.
41. Pine Gene Index PGI5.0 database [http://www.tigr.org/tigrscripts/tgi/T index.cgi?species=pine]

42. Davuluri RV, Sun H, Palaniswamy SK, Matthews N, Molina C, Kurtz M, Grotewold E: AGRIS: Arabidopsis gene regulatory information server, an information resource of Arabidopsis cis-regulatory elements and transcription factors. BMC Bioinformatics 2003, 4:25.

43. Girke T, Lauricha J, Tran H, Keegstra K, Raikhel N: The Cell Wall Navigator database. A systems-based approach to organismunrestricted mining of protein families involved in cell wall metabolism. Plant Physiol 2004, 1 36:3003-3008.

44. Raes J, Rohde A, Christensen JH, Van de Peer $Y$, Boerian $W$ Genome-wide characterization of the lignification toolbox in Arabidopsis. Plant Physiol 2003, 133:1051-1071.

45. Li F, Zhang D, Fujise K: Characterization of fortilin, a novel antiapoptotic protein. J Biol Chem 200I, 276:47542-47549.

46. Pay $A$, Heberle-Bors $E$, Hirt $H$ : An alfalfa CDNA encodes a protein with homology to translationally controlled human tumor protein. Plant Mol Biol 1992, 19:50I-503.

47. Sage-Ono K, Ono M, Harada $\mathrm{H}$, Kamada $\mathrm{H}$ : Dark-induced accumulation of mRNA for a homolog of translationally controlled tumor protein (TCTP) in Pharbitis. Plant Cell Physiol 1998, 39:357-360

48. Campbell M, Sederoff RR: Variation in lignin content and composition. Plant Physiol 1996, I I 0:3-13.

49. Peleman J, Saito K, Cottyn B, Engler G, Seurinck J, Van Montagu M, Inze $D$ : Structure and expression analyses of the S-adenosylmethionine synthetase gene family in Arabidopsis thaliana. Gene 1989, 84:359-369.

50. Shen B, Li C, Tarczynski MC: High free-methionine and decreased lignin content result from a mutation in the Arabidopsis S-adenosyl-I-methionine synthetase 3 gene. Plant J 2002, 29:37I-380.

5I. Sanchez-Aguayo I, Rodriguez-Galan JM, Garcia R, Torreblanca J, Pardo JM: Salt stress enhances xylem development and expression of S-adenosyl-L-methionine synthase in lignifying tissues of tomato plants. Planta 2004, 220:278-285.

52. Espartero J, Pintor-Toro JA, Pardo JM: Differential accumulation of S-adenosylmethionine synthetase transcripts in response to salt stress. Plant Mol Biol 1994, 25:217-227.

53. Schröder G, Eichel J, Breining S, Schröder J: Three differentially expressed S-adenosylmethionine synthetase from Catharantus roseus : molecular and functional characterization. Plant Mol Biol 1997, 33:21 I-222.

54. Gramene database [http://www.gramene.org/]

55. Lindroth AM, Saarikoski P, Flygh G, Clapham D, Gronroos R, Thelander M, Ronne $\mathrm{H}$, von Arnold S: Two S-adenosylmethionine synthetase-encoding genes differentially expressed during adventitious root development in Pinus contorta. Plant Mol Biol 200I, 46:335-346.

56. CCGB biodata database [http://ccgb.umn.edu/biodata/]

57. Lamblin AF, Crow JA, Johnson JE, Silverstein KA, Kunau TM, Kilian A, Benz D, Stromvik M, Endre G, VandenBosch KA, Cook DR, Young ND, Retzel EF: MtDB: a database for personalized data mining of the model legume Medicago truncatula transcriptome. Nucleic Acids Res 2003, 31:196-201.

58. Arborea project [http://www.arborea.ulaval.ca/en]

59. Chang S, Puryear J, Cairney J: A simple and efficient method for isolating RNA from pine trees. Plant Mol Biol Rep 1993, II:113-116.

60. Sambrook J, Fritsch EF, Maniatis T: Molecular Cloning: A Laboratory Manual 2nd edition. Plainview, NY: Cold Spring Harbor Laboratory Press; 1989

61. Yang GS, Stott JM, Smailus D, Barber SA, Balasundaram M, Marra MA Holt RA: High-throughput sequencing: a failure mode analysis. BMC Genomics 2005, 6:2.

62. Ewing B, Hillier L, Wendl MC Green P. Base-calling of automated sequencer traces using phred. I. Accuracy assessment. Genome Res 1998, 8:175-185.

63. Phrap software [http://www.phrap.org]

64. National Center for Biotechnology Information [http:// www.ncbi.nlm.nih.gov/]

65. Altschul SF, Madden TL, Schäffer AA, Zhang J, Zhang Z, Miller W, Lipman DJ: Gapped BLAST and PSI-BLAST: a new generation of protein database search programs. Nucleic Acids Res 1997, 25:3389-3402. 
66. The Institute for Genomic Research [http://www.tigr.org/]

67. Brenner ED, Stevenson DW, McCombie RW, Katari MS, Rudd SA, Mayer KF, Palenchar PM, Runko SJ, Twigg RW, Dai G, Martienssen RA, Benfey PN, Coruzzi GM: Expressed sequence tag analysis in Cycas, the most primitive living seed plant. Genome Biol 2003, 4:R78.

68. Sputnik database [http://sputnik.btk.fi/]

69. The Arabidopsis Information Resource [http://www.arabidop sis.org]

70. Rice Genome Annotation Database [http://www.tigr.org/tdb/ e2kl/osal/]

7I. EMBOSS [http://emboss.sourceforge.net/]

Publish with Bio Med Central and every scientist can read your work free of charge

"BioMed Central will be the most significant development for disseminating the results of biomedical research in our lifetime. " Sir Paul Nurse, Cancer Research UK

Your research papers will be:

- available free of charge to the entire biomedical community

- peer reviewed and published immediately upon acceptance

- cited in PubMed and archived on PubMed Central

- yours - you keep the copyright
BioMedcentral 